\title{
Crosslinking as an Efficient Tool for Decreasing Moisture Sensitivity of Biobased Nanocomposite Films
}

\author{
Jari Vartiainen, Ali Harlin
}

VTT Technical Research Centre of Finland, Espoo, Finland.

Email: jari.vartiainen@vtt.fi

Received March 17 $7^{\text {th }}$ 2011; revised March 25 $5^{\text {th }}$ 2011; accepted March $29^{\text {th }}, 2011$.

\begin{abstract}
Chitosan-nanoclay bio-hybrid films were successfully crosslinked with glutaraldehyde, genipin and glyoxal. Moisture sensitivity of films decreased as a result of crosslinking which led to improved barrier properties against water vapor and oxygen. Films containing chitosan $\left(6.6 \mathrm{~g} / \mathrm{m}^{2}\right)$ with genipin $\left(3.3 \mathrm{~g} / \mathrm{m}^{2}\right)$ and nanoclay $\left(6.6 \mathrm{~g} / \mathrm{m}^{2}\right)$ had water vapor transmission rate of $72 \mathrm{~g} \times 100 \mu \mathrm{m} /\left(\mathrm{m}^{2} \times 24 \mathrm{~h}\right)$ which was 34\% lower as compared to pure chitosan and $30 \%$ lower as compared to chitosan/nanoclay without crosslinkers. Glyoxal induced crosslinking resulted in $92 \%$ reduction in oxygen transmission rate at $80 \%$ relative humidity as compared to pure chitosan films. Oxygen transmission through glyoxal $\left(3.3 \mathrm{~g} / \mathrm{m}^{2}\right)$ treated chitosan/nanoclay film was $2.8 \mathrm{~cm}^{3} \times 100 \mu \mathrm{m} /\left(\mathrm{m}^{2} \times 24 \mathrm{~h}\right)$ which was $53 \%$ lower as compared to chitosan/nanoclay without crosslinkers. In addition, nanoclay and especially glyoxal crosslinking prevented the water vapor sorption of chitosan considerably. Crosslinking may be used as an efficient tool for enhancing the exploitability of naturally hydrophilic biopolymers towards new high-value applications, such as food packaging.
\end{abstract}

Keywords: Chitosan, Nanoclay, Crosslinking, Barrier, Packaging, Glutaraldehyde, Genipin, Glyoxal

\section{Introduction}

Green economy, also referred to as biobased economy, utilizes biomass derived raw materials for high-volume applications, such as packaging. Barrier properties are extremely important for biobased food packaging materials as both gas and water vapor transmission through packaging reduce the quality of food resulting shorter shelf-lives, increased costs and eventually more waste. Nanoclays (or nanolayered silicates) such as hectorite, saponite and montmorillonite are promising additives with high aspect ratio and surface area [1-3]. Due to their unique platelet-like structure nanoclays have been widely studied as regards the barrier properties. Chitosan is a polysaccharide prepared by the N-deacetylation of chitin, the second most abundant natural biopolymer after cellulose. As chitosan is both hydrophilic and cationic in acidic conditions, it has usually good miscibility with negatively charged nanoclays. Chitosan chains may easily intercalate into the clay interlayer by means of cationic exchange [4]. Chitosan/layered silicate nanocomposites have been used to improve the barrier properties against oxygen, water vapor, grease and UV-light transmission as well as the mechanical, thermal and antimicrobial properties [5-9]. Studies on the barrier properties of polymer/layered silicate nanocomposites have traditionally focused on systems with low organoclay contents. Recently, it has been reported that nanoclays can produce substantial improvements in barrier properties over the full range of compositions even up to organoclay content of $80 \mathrm{vol} \%$ without loosing the flexibility and transparency [10]. Correspondingly, we have recently demonstrated an $88 \%$ improvement in the oxygen barrier properties of chitosan films in high humidity conditions with $67 \mathrm{wt} \%$ of nanoclay. The main goal of this work was to verify the effects of crosslinking on the barrier properties of chitosan in high humidity. Glutaraldehyde, genipin and glyoxal were selected as crosslinking agents due to their well-recognised efficiency in cross- linking chitosan [11-15].

\section{Experimental}

\subsection{Materials}

Chitosan was obtained from Fluka BioChemika (low-vis- 
cous with a molecular weight of $150 \mathrm{kDa}$ ) and hydrophilic bentonite nanoclay (Nanomer PGV) from Aldrich. According to manufacturer, nanoclay was untreated (no organic modification) hydrophilic clay (> 98\% montmorillonite) with aspect ratio of 150 - 200. Glutaraldehyde, 25\% solution, was obtained from Merck-Schuchardt, genipin powder from Challenge Bioproducts and glyoxal, 40\% solution, from Sigma-Aldrich.

\subsection{Preparation of Nanocomposite Films}

$1 \%$ nanoclay was swelled in $50 \mathrm{~mL}$ of distilled water and dispersed using ultrasonification tip (Branson Digital Sonifier) for $10 \mathrm{~min}$. The dispersion was added into 50 $\mathrm{mL}$ of $1 \%$ chitosan in $1 \%$ acetic acid, followed by sonication for $10 \mathrm{~min}$. Finally, $0.25 \%$ or $0.025 \%$ crosslinker (glutaraldehyde, genipin or glyoxal) was dissolved in 100 $\mathrm{mL}$ of ethanol and added under rigorous mixing. $15 \mathrm{~mL}$ of each solution was cast onto polystyrene Petri dish $(\varnothing$ $8.5 \mathrm{~cm}$ ) and dried at room temperature. The obtained films were peeled off from the Petri dishes and stored at room temperature and 50\% relative humidity before tests. The composition of the films can be found from Table 1.

\subsection{Viscosity}

Viscosity increment of chitosan solutions after adding crosslinkers was measured using Brookfield Model DVIII Rheometer at $23^{\circ} \mathrm{C}$ with spindel DIN87, model LV and rotation speed of $25 \mathrm{rpm}$.

Table 1. Composition of films expressed as grammages of each component in film.

\begin{tabular}{|c|c|}
\hline Crosslinker & Crosslinker/nanoclay/chitosan $\left[\mathrm{g} / \mathrm{m}^{2}\right]$ \\
\hline- & $0 / 0 / 6.6$ \\
\hline- & 0/6.6/6.6 \\
\hline Glutaraldehyde & 3.3/6.6/6.6 \\
\hline Glutaraldehyde & $0.3 / 6.6 / 6.6$ \\
\hline Glutaraldehyde & $3.3 / 0 / 6.6$ \\
\hline Glutaraldehyde & $0.3 / 0 / 6.6$ \\
\hline Genipin & 3.3/6.6/6.6 \\
\hline Genipin & 0.3/6.6/6.6 \\
\hline Genipin & $3.3 / 0 / 6.6$ \\
\hline Genipin & $0.3 / 0 / 6.6$ \\
\hline Glyoxal & 3.3/6.6/6.6 \\
\hline Glyoxal & $0.3 / 6.6 / 6.6$ \\
\hline Glyoxal & $3.3 / 0 / 6.6$ \\
\hline Glyoxal & $0.3 / 0 / 6.6$ \\
\hline
\end{tabular}

\subsection{Scanning Electron Microscopy (SEM)}

Structures of pure nanoclay in sonicated dispersions were analyzed using scanning electron microscopy (SEM, LEO DSM 982 Gemini FEG-SEM). SEM samples of aqueous dispersions of pure nanoclay were prepared by spreading dispersions on a polyvinyl amine premodified silica surface using fast spinning (2800 rpm for $1 \mathrm{~min}$ ). Typically, no conductive coating was applied on the specimen prior SEM imaging. However, in some cases a thin layer $(\sim 10 \mathrm{~nm})$ of platinum was sputter coated on the surface to improve conductivity and stability of the specimen. The SEM analyses of the aqueous dispersions were conducted using electron energies of $1.0 \mathrm{kV}$ and 2.0 $\mathrm{kV}[16]$.

\subsection{Color}

Hunter a- and b-values were measured using a colorimeter (CR200 Minolta Chroma Meter, Minolta Camera Co., Osaka, Japan). The values indicate the color directions: +a (magenta), -a (green), +b (yellow) and -b (blue). Color values were determined randomly at three different positions on each film.

\subsection{X-Ray Diffraction (XRD)}

X-ray diffraction was used to determine the interlayer distance of layered nanoclays and crosslinked chitosan nanocomposites. Interlayer distances were calculated by the Bragg's equation: $2 d \sin \theta=\lambda$, where $d$ is the interlayer distance, $2 \theta$ is the diffraction angle and $\lambda$ is the wavelength of the X-ray $(\lambda=1.542 \AA)$. X-ray diffractograms were run from the samples using Philips X'Pert MPD diffractometer, powder method and Cu X-ray tube.

\subsection{Water Contact Angle}

Water contact angle of the film surface was measured using CAM200 equipment (KSV Instruments, Finland) in test conditions of $23^{\circ} \mathrm{C}$ and $50 \%$ relative humidity after incubation for $2 \mathrm{~s}$.

\subsection{Water Vapor Transmission}

Water vapor transmission rates of the films were determined gravimetrically using a modified ASTME-96 procedure. Samples with a test area of $25 \mathrm{~cm}^{2}$ were mounted on a circular aluminium dish (H.A. Buchel V/H, A.v.d. Korput, Baarn-Holland 45 M-141), which contained water. Dishes were stored in test conditions of $23^{\circ} \mathrm{C}$ and $50 \%$ relative humidity and weighed periodically until a constant rate of weight reduction was attained.

\subsection{Oxygen Transmission}

Oxygen transmission measurements were performed with Oxygen Permeation Analyser Model 8001 (Systech In- 
struments Ltd. UK). The tests were carried out at $23^{\circ} \mathrm{C}$ and $80 \%$ relative humidity.

\subsection{Water Vapor Sorption}

Water vapor sorption isotherms were measured at $20^{\circ} \mathrm{C}$ with a dynamic water vapor sorption device (DVS-1, Surface Measurement Systems, UK). The device contained a microbalance and a humidity-regulated sample module within a temperature controlled chamber. Humidity was controlled by mixing dry and saturated (with water vapor) nitrogen gases, which flowed through sample and reference (with an empty pan) cells. The weight of the sample was recorded once a minute until the equilibrium was reached.

\section{Results and Discussion}

Typically, the viscosity of the solutions increases as a function of crosslinking and molecular weight. The viscosity measurements indicated that after adding the crosslinkers the chitosan solutions finally converted into a crosslinked gel [17]. Reaction between glutaraldehyde and amino groups of chitosan took place immediately whereas the crosslinking induced by glyoxal and especially genipin proceeded considerably slower. In each case the final product formed gels with viscosity over the range of measurement (Table 2).

Nanoclay was delivered as dry powder with particle size $<25 \mu \mathrm{m}$. According to manufacturer, the nanoclay was composed of high purity aluminosilicate minerals, intended for use as additive to hydrophilic polymers such as polyvinylalcohols, polysaccharides and polyacrylic acids. When fully dispersed, the nanoclay was supposed to form nanocomposites with the host polymers. Hydrophilic nanoclay was dispersed using ultrasonic energy in aqueous suspension. Chitosan dissolved in $1 \%$ acetic acid was then added to the mixture for adsorption to the separated nanoclay sheets. After adding crosslinkers, the nanocomposite films were obtained upon drying. Thickness of the films varied between 8 and $15 \mu \mathrm{m}$. Acidic $\mathrm{pH}$ was necessary for the protonation of amino groups of

Table 2. Viscosity (mPas) of $2 \%$ chitosan in $1 \%$ acetic acid with $1 \%$ crosslinker measured 1,150 and 500 min after adding the crosslinker.

\begin{tabular}{|c|c|c|c|}
\hline Crosslinker & $1 \mathrm{~min}$ & $150 \mathrm{~min}$ & $500 \mathrm{~min}$ \\
\hline - & 180 & 194 & 184 \\
\hline glutaraldehyde & $\begin{array}{l}>10000 \\
\text { (gelling) }\end{array}$ & $\begin{array}{l}>10000 \\
\text { (gelling) }\end{array}$ & $\begin{array}{l}>10000 \\
\text { (gelling) }\end{array}$ \\
\hline genipin & 160 & 257 & $\begin{array}{l}>10000 \\
\text { (gelling) }\end{array}$ \\
\hline glyoxal & 165 & $\begin{array}{l}>10000 \\
\text { (gelling) }\end{array}$ & $\begin{array}{l}>10000 \\
\text { (gelling) }\end{array}$ \\
\hline
\end{tabular}

chitosan. Adsorption process was mainly controlled by a cationic exchange mechanism due to the coulombic interactions between the positive amino groups of chitosan and the negative sites in the clay structure. Since chitosan contains amino and hydroxyl groups, it can form strong intermolecular hydrogen bonds with the silanol edges of the nanoclays, which leads to the strong affinity between the matrix and silicate layers [4].

As can be seen in Figure 1(a), dry nanoclay powder consisted of round particles with coarse and platelety surface. Diameters of nanoclay particles varied between 3 and $25 \mu \mathrm{m}$. By ultrasonic dispersing the nanoclay platelets were effectively ripped off and uniformly distributed on the surface. Previous studies have demonstrated that nanoclay platelets could easily orient parallel to the surface of especially solution cast coatings $[18,19]$. The diameter of the intercalated nanoplatelets was $<400$ nm (Figure 1(b)).

Chitosan dissolved in acetic acid formed completely

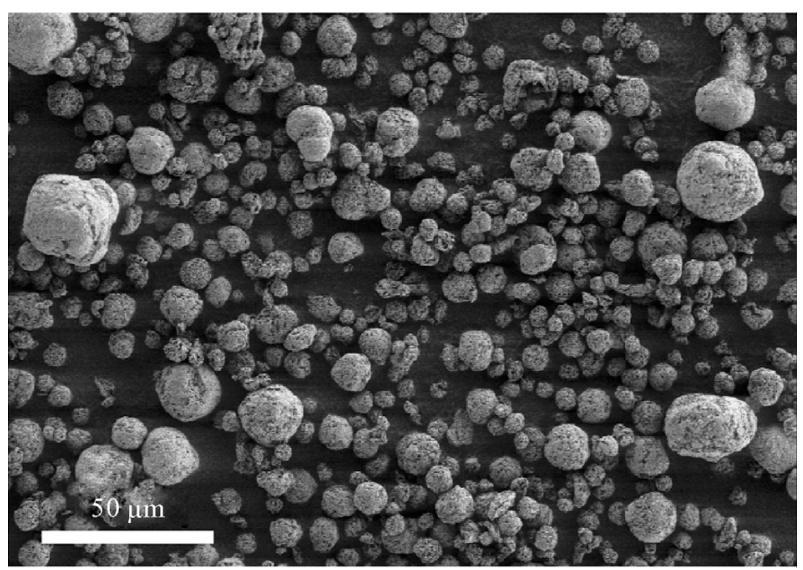

(a)

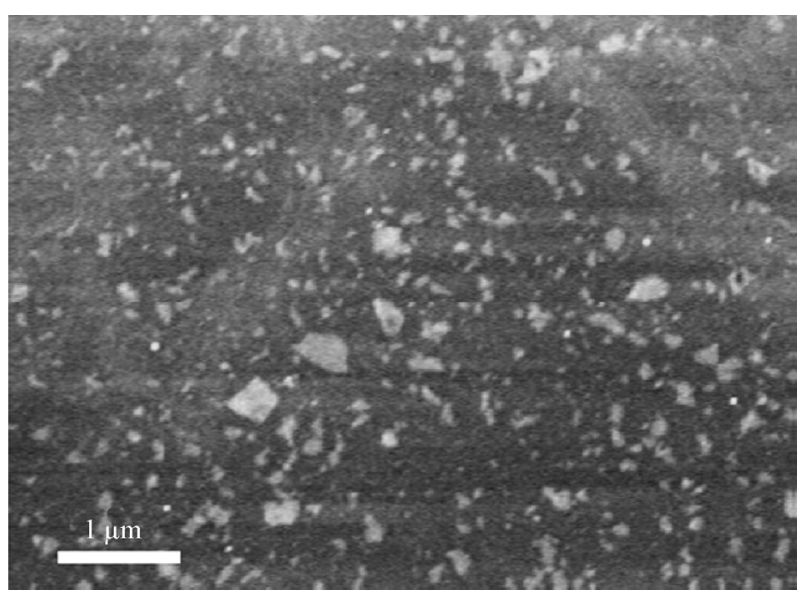

(b)

Figure 1. SEM images of (a) Typical nanoclay aggregates prior dispergation and (b) Spincoated nanoclay platelets after ultrasonic dispergation. 
transparent and colorless films. Also the crosslinker solutions were colorless prior the reaction with chitosan. Nanoclay addition made films slightly opaque and yellowish but still transparent. Glutaraldehyde crosslinking led to an intensive yellow color which was proportional to the amount of crosslinker [11]. Genipin is a raw material for gardenia blue pigment preparation, thus the reaction between genipin and amino groups of chitosan produced dark green-blue films [12]. The color formation was attributed to double bonds in the genipin crosslinking molecules [14]. Glyoxal reacted with chitosan did not produce any measurable or visible color changes as compared to equal films without crosslinker or nanoclay. However, glyoxal slightly improved the color of nanoclay containing films (Figure 2).

Crosslinking typically reduces the solubility and in this case the films containing crosslinkers were completely insoluble in 1\% acetic acid. Chitosan films without nanoclay and crosslinkers dissolved in 3 min under constant mixing whereas the other films were intact after 60 days of immersion. Interestingly, also nanoclay containing chitosan film without crosslinkers kept its shape for 2 months in $1 \%$ acetic acid. Probably the clay sheets prevented the solvent diffusion and the coulombic interactions between the positive amino groups of chitosan and the negative sites in the clay bound the components tightly together.

Intercalated structures are formed when extended chitosan chains are delaminated between the nanoclay layers. The result is a well-ordered multilayer structure of alternating biopolymeric and inorganic layers with a repeat interlayer distance (d-value) between them. The d-values were measured by XRD using the Braggs's equation. The pure powdery nanoclay had an interlayer distance of 1.2 $\mathrm{nm}$. By sonication, the d-values were increased to $1.6 \mathrm{~nm}$. These results are consistent with our earlier studies [8]. As previously established, the thickness of the individual sheet of chitosan chain is $0.38 \mathrm{~nm}[20,21]$ In this case, the diffractograms support the intercalation of chitosan in a monolayer configuration. Monolayer adsorption was mainly controlled by a cationic exchange mechanism due to the coulombic interactions between the positive amino groups of chitosan and the negative sites in the clay structure [4,22]. Crosslinking did not have any notable effects on delamination (Figure 3).

Surface wettability of chitosan was improved with nanoclay. This is consistent with our earlier findings where water contact angles of chitosan-nanoclay films decreased as a function of nanoclay content [8]. Crosslinking had positive effect on hydrophobicity and especially

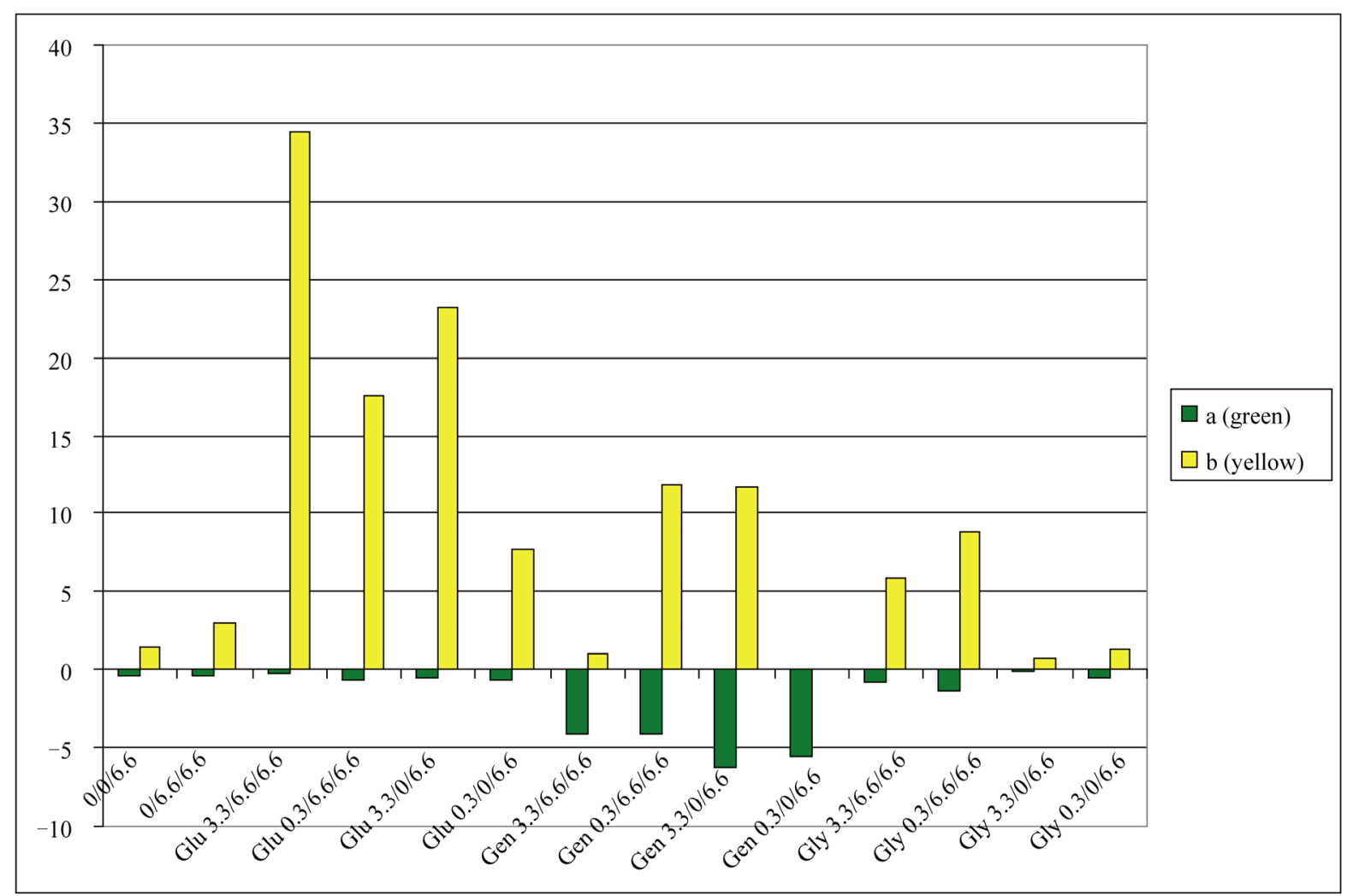

Figure 2. Hunter a- and b-values indicate the color formation (green and yellow) of crosslinked films. Composition of films was expressed as $\mathrm{g} / \mathrm{m}^{2}$ of each component in film (crosslinker/nanoclay/chitosan). 


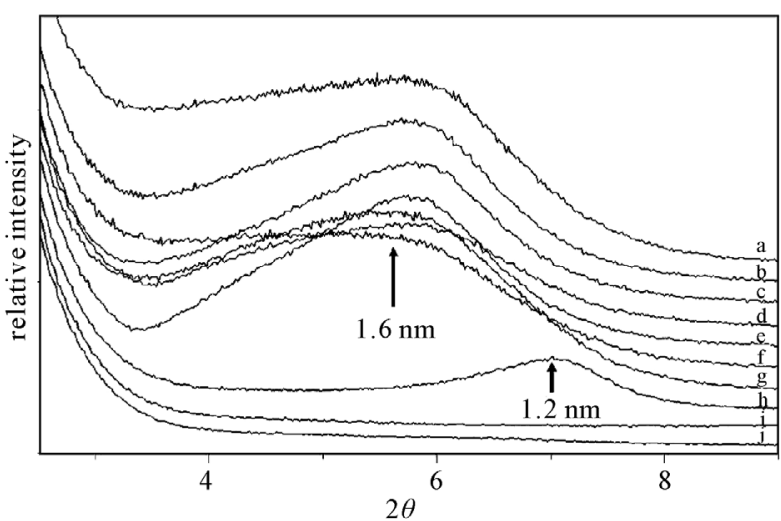

Figure 3. XRD-patterns of chitosan films containing nanoclay and (a) $3.3 \mathrm{~g} / \mathrm{m}^{2}$ glutaraldehyde, (b) $0.3 \mathrm{~g} / \mathrm{m}^{2}$ glutaraldehyde, (c) no crosslinkers, (d) $3.3 \mathrm{~g} / \mathrm{m}^{2}$ genipin, (e) $0.3 \mathrm{~g} / \mathrm{m}^{2}$ genipin, (f) $3.3 \mathrm{~g} / \mathrm{m}^{2}$ glyoxal, (g) $0.3 \mathrm{~g} / \mathrm{m}^{2}$ glyoxal, (h) Pure powdery nanoclay, (i) Chitosan film without nanoclay and crosslinkers, and (j) Silicon base-line.

the higher amount of crosslinkers increased the water contact angles (Figure 4). As water vapor transmission results indicated, nanoclay improved the barrier properties of chitosan films. Crosslinking, however, did not provide any protection against water penetration, except when used in combination with nanoclay. Higher amount of crosslinkers clearly improved the barrier properties of nanoclay containing films. Chitosan films with genipin $\left(3.3 \mathrm{~g} / \mathrm{m}^{2}\right)$ and nanoclay had water vapor transmission rate of $72 \mathrm{~g} \times 100 \mu \mathrm{m} /\left(\mathrm{m}^{2} \times 24 \mathrm{~h}\right)$ which was $34 \%$ lower as compared to pure chitosan and $30 \%$ lower as compared to chitosan/nanoclay without crosslinkers. As was observed earlier, the genipin-crosslinked chitosan networks prepared in acidic conditions typically consist of short chains of cyclic crosslinking bridges [15]. This type of bulky heterocyclic structure may hinder the relaxation and diffusion more than the network crosslinked structure of the glutaraldehyde-crosslinked polymer [23,24]. Hydrophilic chitosan, however, is lacking the full capability of preventing the diffusion of water molecules, thus total barrier effects were lower as compared to more hydrophobic PLA nanocomposites, where nanoclay incorporation decreased the water vapor transmission by about $40 \%-50 \%$ [25].

In general, crosslinking reduces crystallinity of polymers by interfering the formation of crystals. The network junctions can not crystallize, and they may even prevent the neighboring chains from entering into the crystal phase [26]. This should eventually lead to reduced barrier properties due to increased portion of amorphous regions. On the other hand, crosslinking also prevents the humidity induced swelling of chitosan which limits the diffusion increase of water molecules (Figure 5). Marked barrier improvements were achieved with the aid of intercalated nanoclays. Due to intercalation, the effective

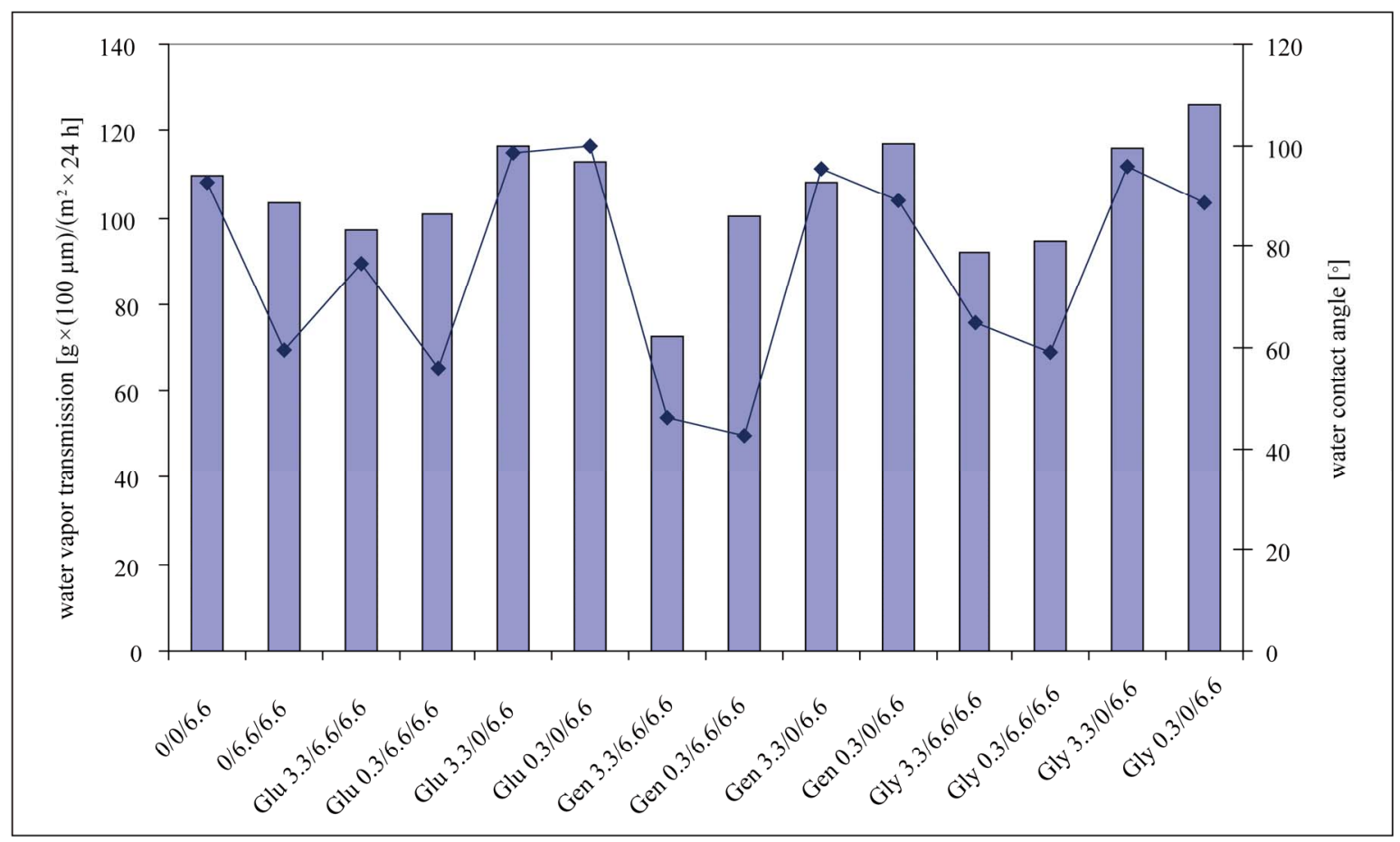

Figure 4. Water vapor transmission rates (columns) versus water contact angles (line) of glutaraldehyde, genipin and glyoxal crosslinked chitosan-nanoclay films (measured at $23^{\circ} \mathrm{C}, 50 \% \mathrm{RH}$ ). Composition of films was expressed as g/m $\mathrm{m}^{2}$ of each component in film (crosslinker/nanoclay/chitosan). 


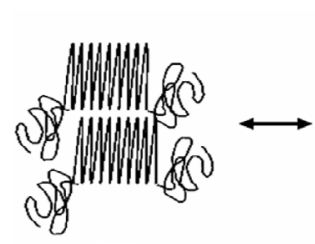

(a)

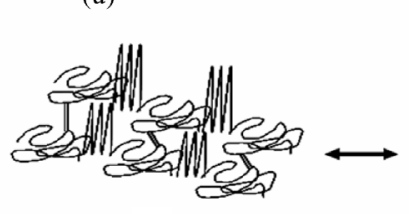

(c)
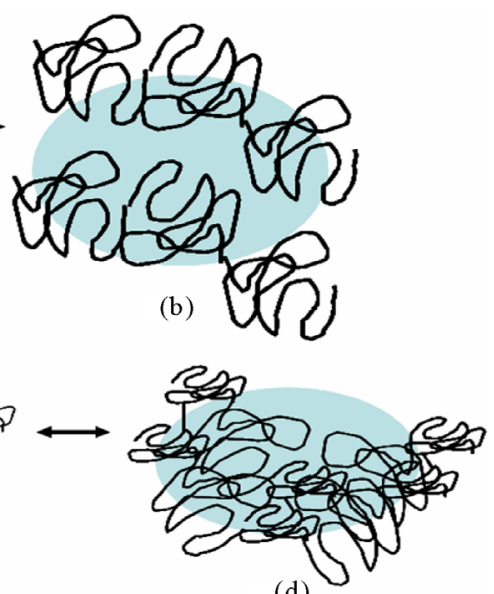

(d)
Figure 5. Effect of crosslinking: (a) Crystalline polymer, (b) Swollen polymer, (c) Crosslinked polymer with reduced crystallinity, (d) Swollen crosslinked polymer where crosslinks limit expansion.

path length for molecular diffusion increased and the path became highly tortuous which decreased both oxygen and moisture transmission through the film [27].

Chitosan and other biopolymers with crystalline structure and hydrogen bonds are typically very good oxygen barriers, but only up to $50 \%$ relative humidity. In high humidity conditions water molecules penetrate between chitosan chains and destroy the hydrogen bonded struc- ture and barrier properties. Nanoclay clearly improved the oxygen barrier properties at $80 \%$ relative humidity (Figure 6). Crosslinking improved barrier properties only when applied together with nanoclay. Glyoxal induced crosslinking of chitosan/nanoclay improved oxygen barrier (92\% reduction in oxygen transmission rate as compared to pure chitosan films). Oxygen transmission through glyoxal $\left(3.3 \mathrm{~g} / \mathrm{m}^{2}\right)$ treated chitosan/nanoclay films was $2.8 \mathrm{~cm}^{3} \times 100 \mu \mathrm{m} /\left(\mathrm{m}^{2} \times 24 \mathrm{~h}\right)$ which was $53 \%$ lower as compared to chitosan/nanoclay films without crosslinkers. These results are slightly better than other studies [8,28-31] where $15 \%$ - $88 \%$ reduction in oxygen transmission rates has been attained with chitosan, PET and PLA-based layered silicate nanocomposites.

Biopolymers, such as chitosan, have a high natural affinity for water, thus films without nanoclay or crosslinkers absorbed almost 35\% of water at $90 \%$ relative humidity. Nanoclay and especially glyoxal crosslinking prevented the sorption considerably (Figure 7). Nanoclay without crosslinkers provided the lowest absorption at lower humidities, whereas glyoxal linked chitosan performed better at higher humidities. As was demonstrated earlier, the glyoxal crosslinked chitosan is more compact and hydrophobic and shows lower degree of swelling as compared to pure chitosan and glutaraldehyde crosslinked chitosan [32]. These results are also consistent with both water vapor and oxygen barrier im-

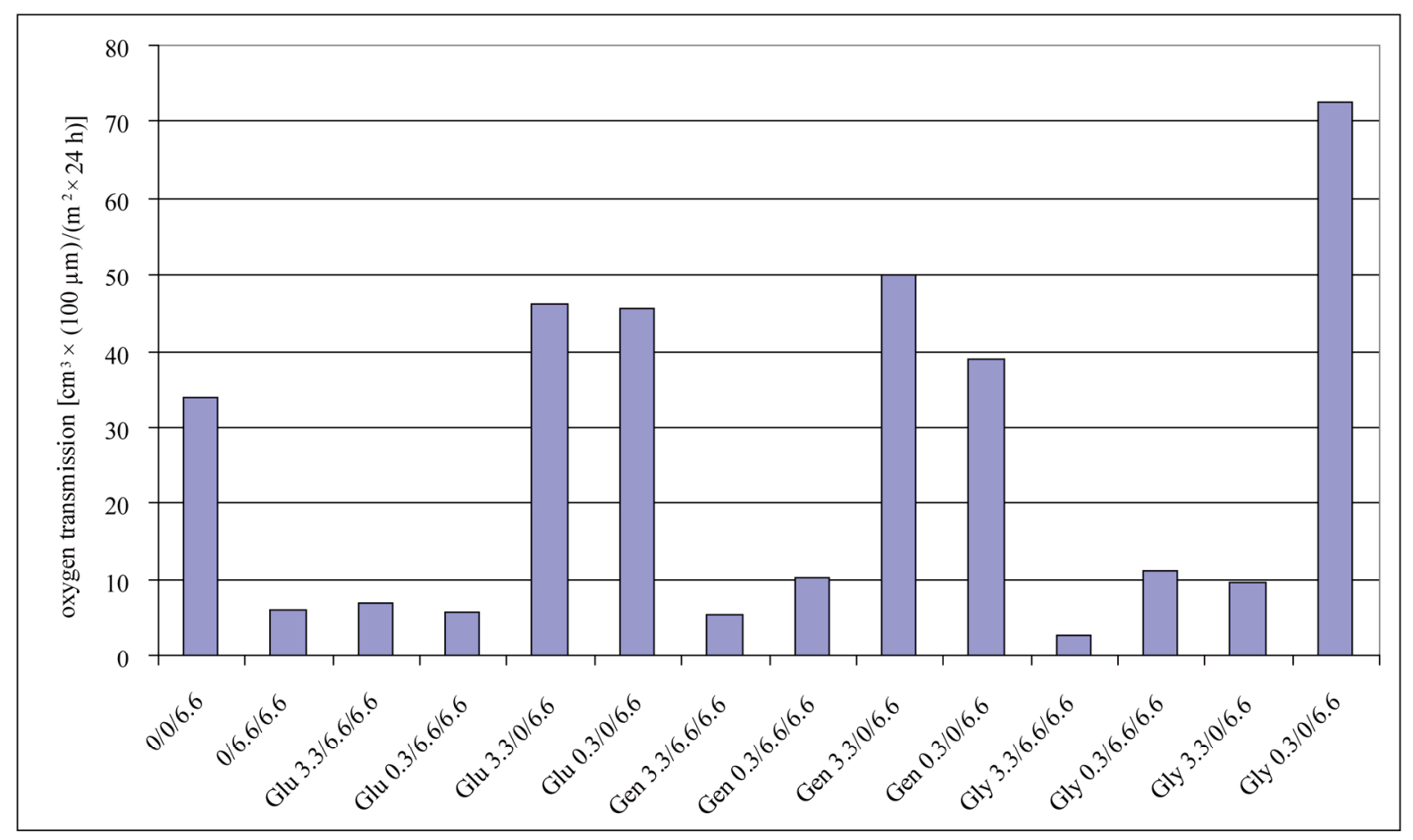

Figure 6. Oxygen transmission rate of glutaraldehyde, genipin and glyoxal crosslinked chitosan-nanoclay films (measured at $\left.23^{\circ} \mathrm{C}, 80 \% \mathrm{RH}\right)$. Composition of films was expressed as $\mathrm{g} / \mathrm{m}^{2}$ of each component in film (crosslinker/nanoclay/chitosan). 


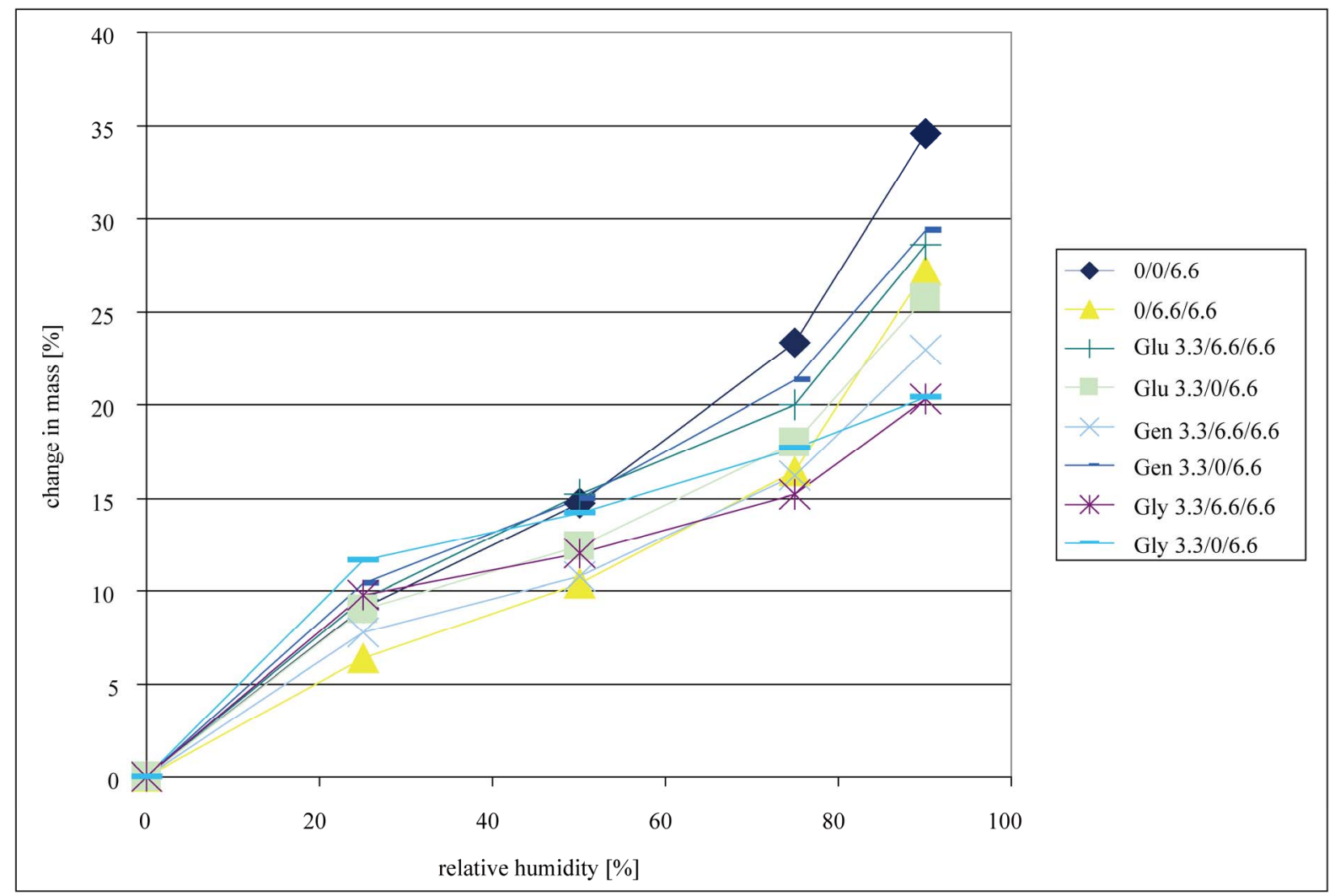

Figure 7. Sorption of glutaraldehyde, genipin and glyoxal crosslinked chitosan-nanoclay films. Composition of films was expressed as $\mathrm{g} / \mathrm{m}^{2}$ of each component in film (crosslinker/nanoclay/chitosan).

provements. The absorbed water molecules weaken the intermolecular interactions, such as hydrogen bonding and crystallinity, leading to reduced barrier properties [6]. Nanoclay and crosslinking prevented the water solubility and swelling of chitosan which increased the number of silicate layers per unit volume eventually resulting in lower permeability.

\section{Conclusions}

Chitosan-nanoclay bio-hybrid films were successfully crosslinked with glutaraldehyde, genipin and glyoxal. Moisture sensitivity of films decreased as a result of crosslinking which led to improved barrier properties against water vapor and oxygen. Crosslinking may be used as an efficient tool for enhancing the exploitability of naturally hydrophilic biopolymers towards new high-value applications, such as food packaging.

\section{Acknowledgements}

The authors thank Heljä Heikkinen, Mari Leino, Juha Hokkanen, Unto Tapper and Sirpa Vapaavuori for their technical help. They also thank all project members as well as VTT's Industrial Biomaterials spearhead programme for funding this study.

\section{REFERENCES}

[1] T. Lan, P. D. Kaviratna and T. J. Pinnavaia, “On the Nature of Polyimide-Clay Hybrid Composites,” Chemistry of Materials, Vol. 6, No. 5, May 1994, pp. 573-575. doi:10.1021/cm00041a002

[2] P. B. Messersmith and E. P. Giannelis, "Synthesis and Barrier Properties of Poly( $\varepsilon$-Caprolactone)-Layered Silicate Nanocomposites," Journal of Polymer Science Part A: Polymer Chemistry, Vol. 33, No. 7, May 1995, pp. 1047-1057. doi:10.1002/pola.1995.080330707

[3] K. Yano, A. Usuki and A. Okada, "Synthesis and Properties of Polyimide-Clay Hybrid Films," Journal of Polymer Science Part A: Polymer Chemistry, Vol. 35, No. 11, August 1997, pp. 2289-2294.

doi:10.1002/(SICI)1099-0518(199708)35:11<2289::AIDPOLA20>3.0.CO;2-9

[4] D. Depan, B. Kumar and R. P. Singh, "Preparation and Characterization of Novel Hybrid of Chitosan-g-PDMS and Sodium Montmorillonite," Journal of Biomedical Materials Research Part B: Applied Biomaterials, Vol. 84, No. 1, January 2008, pp. 184-190. doi:10.1002/jbm.b.30860

[5] X. Wang, Y. Du, J. Yang, X. Wang, X. Shi and Y. Hu, "Preparation, Characterization and Antimicrobial Activity of Chitosan/Layered Silicate Nanocomposites,” Polymer, 
Vol. 47, No. 19, September 2006, pp. 6738-6744. doi:10.1016/j.polymer.2006.07.026

[6] C. Tang, N. Chen, Q. Zhang, K. Wang, Q. Fu and X. Zhang, "Preparation and Properties of Chitosan Nanocomposites with Nanofillers of Different Dimensions," Polymer Degradation and Stability, Vol. 94, No. 1, January 2009, pp. 124-131.

[7] X. Wang, Y. Du, J. Luo, B. Lin and J. F. Kennedy, “Chitosan/Organic Rectorite Nanocomposite Films: Structure, Characteristic and Drug Delivery Behaviour," Carbohydrate Polymers, Vol. 69, No. 1, May 2007, pp. 41-49. doi:10.1016/j.carbpol.2006.08.025

[8] J. Vartiainen, M. Tuominen and K. Nättinen, "Bio-Hybrid Nanocomposite Coatings from Sonicated Chitosan and Nanoclay, Journal of Applied Polymer Science, Vol. 116, No. 6, June 2010, pp. 3638-3647.

[9] J. M. Lagarón and A. Fendler, "High Water Barrier Nanobiocomposites of Methyl Cellulose and Chitosan for Film and Coating Applications," Journal of Plastic Film and Sheeting, Vol. 25, No. 1, January 2009, pp. 47-59.

[10] E. Dunkerley and D. Schmidt, "Effects of Composition, Orientation and Temperature on the $\mathrm{O}_{2}$ Permeability of Model Polymer/Clay Nanocomposites," Macromolecules, Vol. 43, No. 24, December 2010, pp. 10536-10544. doi:10.1021/ma1018846

[11] G. A. F. Roberts and K. E. Taylor, "Chitosan Gels, 3: The Formation of Gels by Reaction of Chitosan with Glutaraldehyde," Die Makromolekulare Chemie, Vol. 190, No. 5, May 1989, pp. 951-960. doi:10.1002/macp.1989.021900504

[12] R. A. A. Muzzarelli, "Genipin-Crosslinked Chitosan Hydrogels as Biomedical and Pharmaceutical Aids," Carbohydrate Polymers, Vol. 77, No. 22, pp. 1-9.

[13] J. Z. Knaul, S. M. Hudson and K. A. M. Creber, “Crosslinking of Chitosan Fibers with Dialdehydes: Proposal of a New Reaction Mechanism," Journal of Polymer Science Part B: Polymer Physics, Vol. 37, No. 1, June 1999, pp. 1079-1094. doi:10.1002/(SICI)1099-0488(19990601)37:11<1079::AI D-POLB4>3.0.CO;2-O

[14] Y. Yuan, B. M. Chesnutt, G. Utturkar, W. O. Haggard, Y. Yang, J. L. Ong and J. D. Bumgardner, "The Effect of Cross-Linking of Chitosan Microspheres with Genipin on Protein Release," Carbohydrate Polymers, Vol. 68, No. 3, April 2007, pp. 561-567. doi:10.1016/j.carbpol.2006.10.023

[15] F. L. Mi, S. S. Shyu and C. K. Peng, "Characterization of Ring-Opening Polymerization of Genipin and pH-Dependent Cross-Linking Reactions Between Chitosan and Genipin,” Journal of Polymer Science Part A: Polymer Chemistry, Vol. 43, No. 10, May 2005, pp. 1985-2000. doi:10.1002/pola.20669

[16] J. Vartiainen, T. Tammelin, J. Pere, U. Tapper and A. Harlin, "Biohybrid Barrier Films from Fluidized Pectin and Nanoclay," Carbohydrate Polymers, Vol. 82, No. 3, October 2010, pp. 989-996. doi:10.1016/j.carbpol.2010.06.031
[17] G. Kumar, J. F. Bristow, P. J. Smith and G. F. Payne, "Enzymatic Gelation of the Natural Polymer Chitosan," Polymer, Vol. 41, No. 6, March 2000, pp. 2157-2168. doi:10.1016/S0032-3861(99)00360-2

[18] S. F. Wang, L. Shen, Y. J. Tong, L. Chen, I. Y. Phang, P. Q. Lim and T. X. Liu, "Biopolymer Chitosan/Mont- morillonite Nanocomposites: Preparation and Characterization,” Polymer Degradation and Stability, Vol. 90, No. 1, October 2005, pp. 123-131.

doi:10.1016/j.polymdegradstab.2005.03.001

[19] M. M. Malwitz, S. Lin-Gibson, E. K. Hobble, P. D. Butler and G. Schmidt, "Orientation of Platelets in Multilayered Nanocomposite Polymer Films,” Journal of Polymer Science Part B: Polymer Physics, Vol. 41, No. 24, December 2003, pp. 3237-3248.

[20] G. L. Clark and A. F. Smith, "X-Ray Diffraction Studies of Chitin, Chitosan and Derivatives,” Journal of Physical Chemistry, Vol. 40, No. 7, 1936, pp. 863-879. doi:10.1021/j150376a001

[21] M. Darder, M. Colilla and E. Ruiz-Hitzky, "Biopolymer-Clay Nanocomposites Based on Chitosan Intercalated in Montmorillonite," Chemistry of Materials, Vol. 15, No. 20, October 2003, pp. 3774-3780. doi:10.1021/cm0343047

[22] M. Darder, M. Colilla and E. Ruiz-Hitzky, "ChitosanClay Nanocomposites: Application as Electrochemical Sensors," Applied Clay Science, Vol. 28, No. 1-4, pp. 199- 208.

[23] H.-C. Liang, W.-H. Chang, K.-J. Lin and H.-W. Sung, "Genipin-Crosslinked Gelatin Microspheres as a Drug Carrier for Intramuscular Administration: In vitro and in vivo studies," Journal of Biomedical Materials Research Part A, Vol. 65A, No. 2, May 2003, pp. 271-282. doi:10.1002/jbm.a.10476

[24] J. D. Wind, S. M. Sirard, D. R. Paul, P. F. Green, K. P. Johnston and W. J. Koros, "Relaxation Dynamics of $\mathrm{CO}_{2}$ Diffusion, Sorption, and Polymer Swelling for Plasticized Polyimide Membranes,” Macromolecules, Vol. 36, No. 17, August 2003, pp. 6442-6448. doi:10.1021/ma034359u

[25] C. Thellen, C. Orroth, D. Froio, D. Ziegler, J. Lucciarini, R. Farrell, N. A. D'souza and J. A. Ratto, "Influence of Montmorillonite Layered Silicate on Plasticized Poly (L-Lactide) Blown Films,” Polymer, Vol. 46, No. 25, November 2005, pp. 11716-11727. doi:10.1016/j.polymer.2005.09.057

[26] C. M. Roland and C. A. Aronson, "Crystallization of Polydimethylsiloxane End-Linked Networks,” Polymer Bulletin, Vol. 45, No. 4-5, December 2000, pp. 439-445. doi:10.1007/s002890070019

[27] O. O. Christopher and M. Lerner, "Nanocomposites and Intercalation Compound, Encyclopedia of Physical Science and Technology,” 3rd Edition, Academic Press, San Diego, 2001.

[28] Z. Ke and B. Yongping, "Improve the Gas Barrier Property of PET Film with Montmorillonite by In Situ Interlayer Polymerization,” Materials Letters, Vol. 59, No. 27, November 2005, pp. 3348-3351. 


\section{doi:10.1016/j.matlet.2005.05.070}

[29] J. Lange and Y. Wyser, "Recent Innovations in Barrier Technologies for Plastic Packaging-A Review,” Packaging Technology and Science, Vol. 16, No. 4, July/August 2003, pp. 149-158.

[30] S. S. Ray, K. Yamada, M. Okamoto and K. Ueda, "New Polylactide-Layered Silicate Nanocomposites. 2. Concurrent Improvements of Material Properties, Biodegradability and Melt Rheology,” Polymer, Vol. 44, No. 3, February 2003, pp. 857-866.

[31] J. H. Chang, Y. Uk-An and G. S. Sur, "Poly(Lactic Acid)
Nanocomposites with Various Organoclays. I. Thermomechanical Properties, Morphology, and Gas Permeability,” Journal of Polymer Science Part B: Polymer Physics, Vol. 41, No. 1, January 2003, pp. 94-103. doi:10.1002/polb.10349

[32] K. C. Gupta and F. H. Jabrail, "Glutaraldehyde and Glyoxal Cross-Linked Chitosan Microspheres for Controlled Delivery of Centchroman," Carbohydrate Research, Vol. 341, No. 6, May 2006, pp. 744-756. doi:10.1016/j.carres.2006.02.003 